\title{
Uma Nova Faculdade de Direito no Brasil
}

Roberto Mangabeira Unger'

\section{Objetivo e âmbito desse memorando}

Consultado sobre a organização e o programa de uma nova faculdade de direito no Brasil, prefiro tratar do tema com proposta ampla, a ser adaptada tanto às limitações materiais que enfrentamos quanto às regras impostas pelas autoridades federais. "Nenhum vento ajuda a quem nāo sabe a que porto veleja", escreveu Montesquieu.

Minha proposta não evoca uma utopia longínqua. Tudo que proponho poderia ser executado dentro da realidade brasileira atual, em pouco tempo, se forem flexibilizadas as exigências curriculares em vigor. Grande parte do projeto pode, porém, reconciliar-se com essas normas. E na medida em que parte do projeto conflite com elas, o conflito dá a base para pleitear a revisão das regras. Insisto: nesse assunto, como em todos, o objetivo primordial, e o problema mais difícil a resolver, é saber o que se quer.

O memorando começa com três séries de observações preliminares. A primeira trata da situação geral do ensino jurídico no mundo. A segunda examina a mudança nessa situação que começa a ser provocada pela "globalizaçāo". A terceira se volta para o ensino do direito no Brasil. À luz dessas três ordens de observações, proponho um novo curso de direito no Brasil, organizado em torno de cinco currículos. Esboço os objetivos, temas e métodos de cada um destes currículos e sua relação com os outros quatro.

Ao preparar a argumentação desse memorando, concluí que se impōe uma mudança arrojada. O ensino atual do direito no Brasil, no seu conjunto e como

1 Professor Titular de Direito da Universidade de Harvard. Pensador Social, Político e Jurídico. 
modelo, malogrou, apesar da excelência de muitos esforços individuais. Por outro lado, não há uma alternativa implantada no mundo que se possa tratar como exemplar e adaptar à realidade brasileira. Mais do que qualquer obstáculo prático, pesará contra a proposta sua novidade. É uma antipatia que pode ser agravada pela falta de costume no Brasil de abraçar projetos que não hajam sido referendados antes por alguns dos centros de cultura que nos acostumamos a imitar.

O problema do ensino de direito no Brasil é um caso extremo. Como está, não presta. Não presta nem para ensinar os estudantes a exercer o direito, em qualquer de suas vertentes profissionais, nem para formar pessoas que possam melhorar o nível da discussão dos nossos problemas, das nossas instituições e das nossas políticas públicas. Representa um desperdício, maciço e duradouro, de muitos dos nossos melhores talentos. E frustra os que, como alunos ou professores, participem nele: quanto mais sérios, mais frustrados. A organizaçāo de uma nova escola de direito no Brasil oferece uma oportunidade para mudar esse quadro. E para trazer o Brasil, em um só salto, para a vanguarda da reforma do ensino jurídico no mundo.

\section{Paradoxo do ensino do direito}

O estudo comparado do ensino jurídico no mundo hoje revela um paradoxo. Em muitos países, a maior parte dos alunos que cursam direito, sobretudo as faculdades mais prestigiosas, não pretende exercer o direito, em qualquer forma profissional. Destina-se à gestão das empresas, à burocracia e à política. Caso característico é o do Japão, onde uma só Faculdade - a Faculdade de Direito da Universidade de Tóquio - tem formado, durante geraçōes, o cerne da elite empresarial, política e burocrática da nação.

Nesses países, os alunos procuram as faculdades de direito como porta de entrada na elite nacional. E lá esperam aprender qual o "deal" na sociedade - os pactos fundamentais do poder - e qual a linguagem em que se descreve e se revê este "deal". A quase ausência, fora dos países de fala inglesa, de um ensino universitário genérico e pré-profissional motiva a busca de um outro instrumento para habilitar jovens a entrar nos quadros dirigentes da sociedade. Para isso servem as faculdades de direito.

A forma jurídica de que se revestem os atos do Estado e a proximidade - ainda que às vezes tênue - do debate doutrinário de direito com a discussão nacional de políticas públicas e ideologias fazem do direito um campo natural para obter essa qualificação. Nem mesmo a influência crescente de disciplinas como economia e práticas como administração de empresas empanou essa primazia do direito.

Há, porém, um problema. Frente a alunos que, na sua maioria, não nutrem preocupações profissionalizantes estreitas, o conteúdo do ensino jurídico tem continuado a ser, na maior parte do mundo, o que sempre foi: um escolaticismo doutrinário e exegético, com pouco valor prático para a advocacia e menor valor 
ainda para o entendimento e o manejo dos pacactos ancioanis de poder. É como se, para usar uma analogia da Inglaterra do século 19, os quadros dirigentes nacionais fossem educados com ênfase na capacidade de traduzir Vergílio para o inglês e verter Wordsworth para o latim.

A base de alunos é ampla. As preocupações são amorfas e as ambições amplas. Mas o que faz o professor na aula é pronunciar uma conferência, repleta de tecnicismos, cuja arbitrariedade é mau disfarçada pela sua antigüidade. Não é nem teoria nem prática. Comumente, é apenas a repetição de fórmulas doutrinárias de pouca ou nenhuma utilidade: as três maneiras de interpretar a norma tal, as duas escolas de pensamento sobre o instituto jurídico qual e assim por diante, numa procissão infindável de preciosimos que não podem ser lembrados (apenas efemeramente decorados) porque não podem ser, em qualquer sentido, praticados. Nem sequer praticados como maneira de analisar.

A história do pensamento jurídico ajuda a compreender essa contradição entre o que os alunos buscam e o que os cursos de direito habitualmente oferecem. Repetidamente denunciado, o formalismo doutrinário em direito sempre ressurgiu, qual fênix, das cinzas. Seu cerne mais persistente foi a crença na convergência natural entre dois projetos: o estudo das idéias jurídicas como um sistema que se pudesse analisar por métodos quase dedutivos e a exposição do conteúdo do direito positivo: o direito tal como construído por legisladores e juízes. Expõe-se o direito positivo de modo a fazê-lo parecer uma realização concreta, ainda que falha, daquele sistema de idéias.

Pouco a pouco, essa concepção vem cedendo lugar a uma outra: de que as normas devem ser analisadas com vista aos valores, aos interesses, às políticas públicas subjacentes. Com isso, a discussão se amplia, mas não tanto quanto parece. A discussão dos objetivos é altamente "estilizada". Concede ao jurista a tarefa de melhorar o direito ao interpretá-lo, reportando-o a interesses mais gerais e diminuindo a influência das concessões aos "lobbies". E, como parte do preço desta interpretação saneadora, evitar de questionar as instituições ou de realçar a contingência e as contradições das soluçōes existentes.

Pois é entre estas duas etapas - a do antigo formalismo e a do novo formalismo, se assim podemos chamá-lo - que se encontra hoje a cultura jurídica da maioria dos países, entre elas o Brasil. O ensino jurídico que se desenvolve sob estas influências continua distante tanto de um pensamento verdadeiramente teórico quanto de uma utilidade profissional imediata. Sem servir nem à teoria nem à prática, resvala na tentativa de casar um amontoado de regras - o conteúdo do direito positivo - com um sistema fossilizado de conceitos doutrinários. Sai a alcunha de escolaticismo que lhe apliquei.

A situação do ensino de direito nos Estados Unidos mostra o outro lado do paradoxo. Nas faculdades de direito de primeira ordem dos Estados Unidos, o ensino é mais amplo, na abrangência de suas preocupaçōes e na variedade de 
seus métodos, do que em qualquer outro país no mundo. O direito, pelo menos tal como estudado em algumas destas faculdades, é hoje a única disciplina nos Estados Unidos que não está sob a hegemonia de qualquer ortodoxia metodológica e ideológica. A falta de consenso, manifestada em divergências muitas vezes radicais entre os professores sobre a maneira de abordar o direito, obriga as escolas a exporem os primeiro-anistas a uma variedade de pontos de vista. Discute-se tudo - e às vezes parece que o que se discute menos é o direito em sentido estrito.

Entretanto, nesse mundo de desordem intelectual - às vezes inibidora e às vezes instigante -, a grande maioria dos alunos continua direcionada não só para a advocacia, mas também para uma versāo muito específica dela: a consultoria de grandes empresas proporcionada por grandes firmas de advogados das principais cidades do país. Nestas firmas, a premissa é que os estagiários e jovens advogados são recrutados porque são inteligentes, e até porque sabem analisar, expor e argumentar. Supōe-se, porém, que terão de aprender o ofício on the job. Quanto mais prestígio tem a escola, e mais garantidos os empregos dos alunos, menor a pressão para que o professor se desvie de sua agenda de pesquisa e polêmica social para atender às preocupaçōes profissionalizantes dos alunos.

Aí está o paradoxo. Em muitos países, onde a base de alunos é menos dirigida para a advocacia, o conteúdo do ensino é mais acanhado. E nos Estados Unidos, onde a base tem um destino profissional mais estreito, o ensino nas faculdades mais influentes é o mais amplo, o menos técnico, do mundo. (Será o Brasil de hoje uma exceção? Parece combinar hoje a base relativamente estreita - a maioria dos alunos a caminho de carreiras de direito - e o conteúdo relativamente estreito, em transição do formalismo à antiga para o neoformalismo, a discussão estilizada de políticas públicas como base para a interpretação do direito.)

E qual o significado deste paradoxo? É que há um espaço enorme para mudança. Não há relação estreita entre a procura (o que motiva os alunos) e a oferta (o que as escolas ensinam). Cada um destes dois elementos se desenvolve sob influências próprias, com pouco poder de constranger o outro elemento. Uma análise funcional desta situação não consegue explicá-la. Esta impossibilidade de entender funcionalmente o que ocorre indica uma oportunidade: a situação não é como tem de ser; pode ser mudada. Como melhor aproveitar esta abertura, em proveito dos alunos e do país, é o tema central deste memorando.

\section{O impacto da globalização}

É importante acrescentar ao entendimento desta oportunidade a análise de uma conseqüência da globalização. De grande importância para o futuro do ensino de direito é, porém, pouco comentada, talvez por ser tão óbvia que não é percebida como problema. 
O mundo caminha para a combinação de integração econômica com diversidade política e jurídica. Apesar das idéias que advogam a convergência de todos os países para um mesmo conjunto de instituiçōes e práticas (como faz, nas suas postulações mais radicais, a chamada doutrina neoliberal), o mundo busca manter e aprofundar um potencial de divergência. O direito, dizia Hegel na esteira de Herder, é a organização da vida de um povo em instituiçōes. Povos diferentes, organizações diferentes e, portanto, sistemas diferentes de direito é o que temos e, provavelmente, continuaremos a ter por mais que se multipliquem as trocas de bens, pessoas e idéias entre os nações.

E aí sobrevém o problema singelo a que me referi. Em tal mundo, o advogado, sobretudo na primeira escala da profissão, tem de atuar em relação a problemas transnacionais: problemas que põem indivíduos, empresas e governos de um país em contato com indivíduos, empresas e governos de outros países. Freqüentemente, não basta fiar-se na divisão do trabalho, colaborando com advogados em outros países. É preciso dominar os dois lados, ou os muitos lados, do problema.

Como? Não é possível, sem perder-se num enciclopedismo custoso e estéril, dominar as leis, a jurisprudência, as instituiçōes, as tradiçōes e os métodos de muitos paises. Qual é a fórmula para economizar o esforço e maximizar o entendimento e a capacidade prática?

Há hoje no mundo um repertório limitado de maneiras de organizar cada campo da vida social: o Estado e a política; as relaçōes entre governos, empresas e trabalhadores; e os vínculos entre governos, escolas, famílias e crianças. Depois do colapso do comunismo, não veio a convergência institucional, mas o repertório se estreitou. Esse repertório está organizado como direito e como direito é reproduzido e reformado. Muda-se o mundo ampliando o repertório: acrescentando a ele uma possibilidade institucional que nāo existia antes. E para mudá-lo é preciso compreendê-lo e criticá-lo.

Os grupos de instituiçōes e idéias institucionais que organizam cada possibilidade estabelecida neste repertório ajudam a entender as especificidades do direito de cada país. Ao dominar o repertório, o jurista, ou o advogado prático, consegue traduzir uma linguagem do direito de um país na linguagem do direito de outro país. Consegue distinguir entre diferenças verdadeiras e equivalências funcionais. Consegue, enfim, abrir caminho numa floresia de pormenores e dar forma a um amontoado de acidentes.

É um nível de análise intermediária entre a exegese rasteira das normas de cada país e as abstrações do pensamento político, econômico e social. O estudioso e o praticante do direito precisam saber mover-se nesse nível para poder manejar os problemas que lhe são apresentados no mundo complicado da globalização. Falta ainda, no Brasil ou em qualquer lugar, a escola que lhe ensine como. 


\section{O ensino do direito no brasil}

O problema central do ensino do direito no Brasil é sua fixação numa abordagem ao mesmo tempo enciclopédica, exegética e escolástica do direito brasileiro vigente. É um caso típico de uma cultura jurídica que se encontra, nas suas melhores expressões, a meio caminho entre os dois formalismos - $\mathrm{o}$ antigo e o novo - $\mathrm{a}$ que antes me referi.

Não se pode dizer que seja completamente sem relevância prática. Os alunos costumam aprender conceitos, métodos e regras que são de fato reproduzidos nos tribunais e nas peças que advogados e procuradores escrevem para juízes. Como seria de supor, há um círculo: as melhores escolas produzem determinado tipo de quadro, com determinada maneira de pensar e se expressar. Estas práticas prevalecem nas carreiras públicas do direito, inclusive entre o judiciário. Sua prevalência por sua vez dá pretexto às faculdades para continuar a ensinar como ensinam. E como os países mais admirados de cultura jurídica semelhante - os da Europa - sofrem, em seu ensino de direito, de problemas semelhantes, o continuísmo acaba por parecer quase inevitável.

Quanto mais a prática jurídica se desloca do ambiente jurisdicional para as atividades de consultoria jurídica - inclusive e sobretudo consultoria de grandes empresas - e quanto mais transpōem as fronteiras do Brasil e do direito brasileiro para tratar de problemas transnacionais, menos útil, mesmo para a atividade profissional, o ensino atual se revela.

São justamente estas as preocupações características da elite de advogados e de firmas, no Brasil como em toda parte. O resultado é que, para essa elite, o significado do curso de direito diminui. E o peso da aprendizagem no trabalho, do estudo no estrangeiro e da seleção inicial por critérios não meritocráticos ou informais aumenta.

Outro resultado lento e cumulativo deste acanhamento e tradicionalismo do ensino jurídico no Brasil é a marginalização dos advogados e juristas brasileiros do debate nacional. Deixaram de ser participantes centrais. Seu lugar foi há muito tomado pelos economistas e afins, que pelo menos parecem tratar, ainda que através de prisma estreito e distorcivo, dos problemas do país. Ficaram os juristas de elite reduzidos à condição de técnicos a serviço dos poderosos e endinheirados. Há uma medida provisória a editar? Vamos pô-la em linguagem com mais perspectiva de sobreviver a dúvidas e contestações. Há um negócio a realizar? Vamos enquadrá-lo nas formalidades da lei. Esse papel de amanuense, de escriba passivo e obediente, contrasta, de maneira chocante, com o papel norteador que os advogados e juristas desempenharam em outros periodos da história brasileira.

E daí? Por que se preocupar com a substituição da influência de um grupo profissional por outro? Por duas razões. A primeira razão é que o Brasil precisa do 
império do direito em todas as esferas da vida nacional. Os esforços para acabar com a impunidade, para desprivatizar o Estado, para criar mecanismos que permitam aos governos superar a escolha entre o laissez-faire e a rendição às clientelas, para resguardar trabalhadores e investidores, para identificar e combater as formas mais ou menos veladas de opressão e exclusão na sociedade brasileira - tudo exige uma cultura jurídica capaz de ir ao encontro da realidade social, de imaginála e reconstrui-la como direito. A segunda razão é que, para abrir seu caminho nacional, o Brasil precisa poder repensar e refazer suas instituições. A vocação do pensamento jurídico numa democracia, para além das fronteiras da praxe do advogado, é transformar-se numa prática de imaginação institucional, no terra-a-terra dos problemas imediatos e das possibilidades próximas.

O sentido da proposta neste documento é sugerir um rumo para o ensino do direito que reconcilie a necessidade de dar resposta a este imperativo nacional com a vantagem prática de formar um advogado e um jurista capazes de atuar no ambiente da globalização.

Há uma última razão para insistir: o enorme desperdício de talento consumado pelo atual ensino de direito. Os cursos de direito continuam muito demandados no Brasil. Segundo algumas avaliações, estão mais demandados nos últimos anos, inclusive por muitos dos melhores alunos. Este talento todo encontra nas faculdades de direito um terreno relativamente estéril, apesar dos muitos professores que, individualmente, tentam quebrar o marasmo e oferecer uma alternativa, de idéias e atitudes, a seus alunos.

Nesta situaçāo uma reforma prática do ensino do direito, que capacite o aluno para a prática mais valorizada na nova realidade econômica do país e do mundo e traga o direito de volta para o centro do debate nacional, pode surtir efeito grande e rápido sobre as outras escolas de direito no Brasil. E pode, em pouco tempo, atrair muitos dos melhores professores e alunos e granjear uma reputação hors concours no meio profissional e no conceito público.

\section{Estrutura básica do curso}

Proponho um curso organizado em torno de cinco currículos: (1) o currículo do direito brasileiro, (2) o currículo das disciplinas de apoio e aprofundamento, (3) o currículo das práticas de direito, (4) o currículo da globalização e (5) o currículo das alternativas institucionais.

O aluno normalmente optaria por um mínimo de três e um máximo de quatro dos cinco currículos. Entretanto, se não forem reformadas as normas federais vigentes, o currículo de direito brasileiro teria de ser obrigatório. O currículo das alternativas institucionais poderia ser deslocado do curso de graduaçāo para o de mestrado, ao qual forneceria o eixo e o diferencial. 
O curso poderia ser completado nos cinco anos normais. $O$ ideal, porém, é que os mesmos cursos e créditos pudessem ser obtidos, por um esforço mais intensivo, de quatro ou, até mesmo, três anos. O encurtamento abriria espaço para um ensino universitário pré-profissional de dois anos. Estabelecida esta etapa anterior, o currículo de disciplinas de apoio seria absorvido por ela. Se o currículo das alternativas institucionais passasse para o mestrado ou o currículo das disciplinas de apoio e aprofundamento para o ensino universitário pré-jurídico, o número de currículos do curso de direito passaria de cinco para quatro.

O curso de direito que proponho objetiva formar tanto profissionais de elite, aptos a praticar o direito na época da globalização, quanto quadros dirigentes nos mundos dos negócios, da administração pública e da diplomacia. Nesse seu segundo propósito, será uma alternativa ao curso de administração, capaz de atrair os mais enérgicos e ambiciosos.

Minha hipótese é que a concentração de talentos (ainda que desperdiçados) nas faculdades de direito é tão grande, e a frustração com o curso de direito tamanha, que uma faculdade que represente um grande salto de qualidade logo se tornará um pólo de mobilização, atraindo interesse em todo o país. Para que se possa aproveitar este potencial, é preciso pensar detidamente sobre dois problemas preliminares: um fundamental e genérico; outro, derivado e específico.

Nenhuma concepção programática e metodológica pode suprir o essencjal, as pessoas. Não é possível fundar uma faculdade de direito com uma orientação diferente, como aquela que proponho aqui, e confiar o trabalho, sem mais nem menos, aos mesmos professores que já ensinam nas faculdades existentes. A diferença programática ficará logo reduzida à presença de matérias novas ao mesmo tempo que a introdução destas matérias tem de lutar contra os constrangimentos impostos pelas normas federais. Por outro lado, também não é possível aguardar a formação de um nova geração de estudiosos. Afinal, o problema é que não existem no Brasil as instituições que possam formá-los.

A única maneira prática de romper este círculo vicioso é identificar um núcleo de pessoas que se possam comprometer com este projeto - alguns, iniciantes na carreira acadêmica; outros, já estabelecidos - e consolidar a visão deste núcleo antes de dar início ao curso. O importante é que o núcleo seja intelectualmente forte, tenha clareza sobre o projeto e liberdade para desenvolvê-lo com arrojo. Preenchida essa condição essencial, fica menos perigosa a presença de professores, ainda que numericamente majoritários, que não estejam possuídos pelo mesmo sentimento de tarefa e imbuídos da mesma visão.

A consideração prática subsidiária é que convém pensar sobre como organizar um sistema que permita atrair tanto professores quanto alunos de outras partes do país, facilitando a moradia. A prática de recrutar quase todo o corpo docente e discente de uma escola da população local, embora generalizada no Brasil de hoje, é incompatível com a pretensão de fundar uma instituição que, como as Faculdades de Direito de São Paulo e do Recife no século XIX, exerça uma liderança nacional e ajude a formar quadros dirigentes nacionais. 
Não se trata de obsessão elitista. Trata-se de radicalizar na meritocracia e na inconformidade com o marasmo. O curso que idealizo não se destina a um pequeno quadro de alunos de talento extraordinário. Destina-se a um grupo potencialmente numeroso de estudantes capazes, sérios e trabalhadores. Exige um grau tanto de dedicação quanto de experimentalismo intelectual incomuns na educação brasileira. Tanto melhor. O objetivo não é apenas mudar o ensino do direito. É mudar o Brasil.

\section{Estrutura das aulas e do ensino}

O formato comum das aulas que recomendo é de grupos de 20 a 30 alunos. Entretanto, nos currículos de práticas do direito e no de alternativas institucionais, convém substituir tal número por equipes de trabalho, de seis a dez alunos, conforme explico adiante.

O método predominante do ensino será a combinação da introdução extensiva ou informativa com o aprofundamento seletivo. A ênfase recairá, porém, sobre o segundo destes elementos. A introdução extensiva fornece um mapa geral do campo, mas abandona a mania contraproducente de insistir em abrangência enciclopédica. O resultado dessa mania é ocupar o tempo tanto do professor quanto do aluno com informações que entram na memória e saem dela sem deixar o resquício de uma capacidade analítica fortalecida.

O aprofundamento seletivo é o estudo, dentro de uma disciplina, de conjuntos exemplares de problemas. Não é propriamente um estudo de casos à moda das antigas faculdades de direito e das atuais escolas de negócios nos Estados Unidos. É a investigação persistente de um tema em todas suas ramificações conceituais e práticas. Só através desta experiência é que o aluno aprende a dominar os métodos analíticos, as fórmulas argumentativas e os materiais de pesquisa de determinado campo de ação e pensamento. Sai sentindo-se capacitado, não apenas enchido de informações que está destinado a esquecer.

Esse método híbrido de mapeamento sumário e aprofundamento exemplar deve prevalecer nos currículos do direito brasileiro, das disciplinas de apoio e da globalização. (Volto ao assunto ao concluir minha discussão do currículo de direito brasileiro.)

Já nos currículos das práticas do direito e das alternativas institucionais - o mais profissionalizante e o mais ambicioso intelectualmente - proponho substituir esta abordagem híbrida pela aprendizagem (no caso das práticas do direito) ou pela pesquisa e formulação (no caso das alternativas institucionais ) dentro das pequenas equipes, de seis a dez alunos, que descrevi. Não há propriamente temas exemplares a aprofundar. Há capacidades práticas a emular, no currículo das práticas do direito. E há uma maneira de ver a situação e as possibilidades das sociedades contemporâneas, através da identificaçāo, decomposição, recombinação e renovação de suas instituições, no currículo das alternativas institucionais. 
Não é um ensino para gênios ou por gênios o que proponho. É um ensino para uma elite intelectual, selecionada e orientada meritocraticamente, e caracterizada, sobretudo, pela diligência, flexibilidade e ambição. Aos gênios atribuo a tarefa de atacar o que esse grupo pensar e fizer.

\section{O currículo do direito brasileiro}

Esse primeiro currículo é o que mais se assemelharia ao curso de direito tal como já estabelecido no Brasil. Em princípio, toda a matéria central do direito brasileiro, e mais alguma coisa, seriam abordadas aqui.

$\mathrm{Na}$ medida compatível com as exigências impostas pelas autoridades, ou com o ritmo da reforma destas exigências, proponho as seguintes diretrizes temáticas e metodológicas.

O direito brasileiro seria dividido em grandes setores. Matérias tradicionalmente estudadas em compartimentos diferentes seriam ensinadas de forma integrada. A razão é simples. A divisão atual das disciplinas jurídicas é o fruto de uma história acidental mais do que o produto de uma visão consistente. Estudar o direito societário, por exemplo, primeiro no direito civil e depois no direito comercial não faz muito sentido. Dificulta o entendimento. Conflita tanto com as conveniências da prática quanto com as exigências da teoria.

Inversamente, também não faz muito sentido tratar a chamada parte geral do direito civil, e seus conceitos de pessoa, de ato, e do alcance das regras num curso de cinco anos que aborda Deus e o mundo. Não o justifica o simples fato de ser o direito civil, na nossa tradição, o substrato de que emergiram as outras disciplinas de direito privado e o próprio direito público. O aluno começa e acaba incapaz de distinguir a direção das soluçōes que o direito dá aos problemas da vida social do amontoado de fórmulas e categorias históricas que o direito gerou. E afunda num pantanal de tecnicismos, de que só escapa pela indiferença.

Proponho a seguinte divisão de disciplinas fundamentais.

CONCEITOS E TERMINOLOGIA DO DIREITO BRASILEIRO. Abrange tanto o que tradicionalmente se ensina como "introdução geral ao direito" quanto a chamada parte geral do direito civil. Inclui, também, a terminologia básica do direito público que, historicamente, se definiu por analogia e por contraste ao direito privado.

O PROCESSO. O estudo do direito processual deve abranger, numa só disciplina, o processo civil, o processo penal, a arbitragem e a solução negociada dos conflitos. É importante aprofundar o estudo dos problemas práticos enfrentados pelos juízes e pelos advogados que lidam com eles. E dedicar uma parte do curso às tarefas do Ministério Público. Nenhuma análise do processo pode ser profissionalmente útil, ou intelectualmente interessante, sem que aborde a relação entre o 
ordenamento formal do processo e as estratégias adotadas por advogados, juízes e membros do Ministério Público para funcionar dentro da realidade dos tribunais.

A PESSOA E A FAMÍLIA. Inclui o que na parte geral do direito civil se relaciona com as pessoas tanto físicas quanto jurídicas, bem como o direito de família. E mais o tratamento da pessoa no direito constitucional, no direito internacional privado e no direito internacional público, portanto também tudo que tenha a ver com os direitos humanos. Não faz sentido tratar estes assuntos dentro de disciplinas não só separadas, mas distantes dentro do ensino jurídico. Nem se justifica hoje a separação radical do estudo da tutela nacional e internacional da pessoa - um anacronismo como quase tudo no atual currículo jurídico.

O CAPITAL E OS CONTRATOS. Proponho relativizar a distinção entre o estudo da propriedade e o estudo dos contratos. O aluno será levado a percorrer um itinerário de estágios sucessivos de aprofundamento e detalhamento. No primeiro estágio, propriedade e contrato serão estudados como conceitos correlatos. Dar-se-á atenção especial à desagregação e à recombinação contratuais dos poderes heterogêneos que compõem a propriedade no direito civil moderno - tema que resultará de grande importância prática quando o aluno começar a estudar o mercado financeiro.

Na segunda etapa do ensino, estuda-se todo o espectro de formas de apropriação da riqueza, desde a posse até o domínio unificado e incondicional e desde a apropriação de objetos até a propriedade intelectual e a tentativa de transformar em propriedade o controle das formas mais intangíveis do capital.

Investiga-se a relação entre todo este espectro de formas jurídicas da riqueza e a multiplicidade de fontes de obrigação contratual ou quase contratual entre as pessoas: não só os acordos explícitos mas também os acertos implícitos ou inacabados e as obrigações que eles possam gerar. Neste segundo momento, fica evidente o significado ao mesmo tempo prático e teórico da relação entre o estudo da propriedade e o estudo das obrigações contratuais.

No terceiro estágio, o aluno passa para a fronteira contemporânea do direito de propriedade e do direito contratual. De um lado, estuda a riqueza imaterial, aprofundando a análise da propriedade intelectual. De outro lado, aborda as finanças e a criação de mercados em "derivativos" do direito de propriedade.

A RESPONSABILIDADE CIVIL E O DIREITO DO CONSUMIDOR. NesSa disciplina, estudam-se as obrigações ex delicto e todas as formas de responsabilização que possam resultar em obrigações de indenizar. Aborda-se o direito do consumidor como parte integral da problemática da responsabilidade civil. E compara-se a proteção do consumidor pelo direito civil com sua proteção através da ação reguladora do Estado.

A EMPRESA E O TRABALHADOR. Nessa parte do currículo, seriam incluídos todo o direito societário, boa parte do direito comercial (outra parte ficaria para o capital e os contratos) e o direito do trabalho. O enfoque central seria o estudo 
dos mecanismos usados para associar o capital e o trabalho na produção. O estudo das empresas relegaria a segundo plano as divisōes formais entre diferentes tipos de empresas. Focalizaria o contraste prático e funcional entre empresas controladas por famílias e empresas de capital aberto. E estudaria a relação causal recíproca entre regimes empresariais e estilos de produção ou colaboração.

Já no estudo do direito do trabalho, o contraste conceitual organizador seria entre os regimes coletivos de trabalho e a disciplina legal direta do vínculo empregatício. Em ambos os casos, o estudo trataria de combinar a investigação do regime legal vigente com a análise dos efeitos econômicos e sociais, tanto das soluções estabelecidas quanto das soluçōes alternativas.

O DIREITO PENAL. O direito penal deve ser dividido em três partes. A primeira parte estudaria os conceitos básicos do direito e o pequeno número de regras que perpassam toda a tipologia de crimes. A segunda trataria de normas e práticas usadas para controlar a violência comum, sobretudo aquela que se difunde entre as partes mais pobres e mais desorganizadas da população. É um estudo que tem de abranger a discussão da polícia, das prisões e da natureza e efeitos do encarceramento episódico e quase arbitrário que caracteriza o sistema brasileiro. $\mathrm{Na}$ terceira parte do curso, o tema seria os crimes típicos dos endinheirados (ou aspirantes a tal condição), não só os crimes reconhecidos de colarinho branco, mas também aqueles que resultam da violação do direito de proteção ao consumidor e de repressão ao abuso do poder econômico.

O ESTADO E A POLÍTICA. A maior dificuldade do estudo do direito constitucional no Brasil é o violento contraste entre a profundidade e a importância dos temas em jogo e a ladainha retórica e terminológica a que se reduz grande parte do discurso constitucional. É uma versão agravada do que acontece com o escolaticismo doutrinário em todos os ramos do direito.

A solução não é transformar o direito constitucional em "ciência política". É ordenar o estudo do direito constitucional em torno das grandes opçōes institucionais, feitas ou rejeitadas, explicitando a arquitetura profunda do desenho constitucional. Esta arquitetura pode, em seguida, ser colocada tanto no contexto da história da política brasileira quanto no contexto da história das idéias políticas. Com esta abordagem, a antiga disciplina de "teoria geral do Estado" perde sentido. E o estudo da Constituição pode ser mais facilmente integrado com a análise de como se organiza a política. Dentro desta análise, devem ser abordados a influência da mídia e o uso do dinheiro na política.

TRIBUTAÇÃO E GASTO SOCIAL. Esta parte do currículo incluirá o direito tributário. A inovação mas importante será o estudo do gasto público ao lado do estudo dos tributos. O maior defeito do estudo tradicional dos tributos nas faculdades de direito de todo o mundo é o hábito de estudar a arrecadação independentemente do gasto. Com isso, ofusca-se o sentido da tributação e suprime-se a investigação de práticas e regras que regem o dispêndio da terça parte do produto de um país como o Brasil. 
Qual deve ser o método predominante no ensino deste currículo? Nem a exposição doutrinária - instrumento preferido do escolaticismo predominante - nem o estudo de casos - antiga predileção das escolas de direito nos Estados Unidos - representam a melhor solução. O método tem de guardar relação estreita com a visão que anima o projeto pedagógico. Por isso mesmo, nunca pode ser mais do que uma proposta dirigida ao corpo de professores, que o adotará ou o alterará de acordo com as idéias de cada um.

O método predominante que proponho é a combinação de introduções ou mapeamentos informativos e abrangentes, pelo método convencional de exposições, seguidas por discussões, com o método intensivo, de aprofundamento seletivo e analítico de temas exemplares dentro de cada matéria. A inovaçāo, portanto, está neste elemento intensivo, que exige explicação mais pormenorizada.

Trata-se de adaptar ao ensino do direito as práticas características do ensino mais avançado das ciências. Abandonar-se-ia o enfoque enciclopédico para ter a experiência de domínio sobre um conjunte de problemas e soluções. Por exemplo, dentro da disciplina que estudaria os contratos e o capital, há um conjunto de problemas, de grande interesse intelectual e enorme importância prática, que tem a ver com as obrigaçōes geradas por participaçōes individuais em fundos coletivos, como os planos de saúde ou seguro e os fundos de pensão. Ensejam problemas análogos para o direito, pouco compreendidos. E testam os limites das idéias disponíveis sobre os contratos e a propriedade.

Com este sistema de aprofundamento seletivo em alguns temas exemplares dentro de cada disciplina, o aluno ganha oportunidade melhor para pesquisar e pensar. Trava conhecimento com os materiais da disciplina, as fontes, tanto conhecidas quanto novas, do direito. E colabora com os colegas, já que este aprofundamento seletivo avança, tipicamente, através do trabalho em equipe.

O elemento extensivo nesta abordagem fornece o mapa geral da disciplina, portanto, os rudimentos da informação. Já o elemento intensivo abre a porta para a experiência intelectual. É um procedimento que, adotado no início do curso, no currículo de direito brasileiro, pode ser reproduzido e desdobrado depois, nos outros currículos.

\section{Currículo das disciplinas de apoio e aprofundamento}

O estudo do currículo de direito brasileiro deve ser acompanhado pelo estudo do currículo de disciplinas de apoio, que suprem a ausência, no ensino brasileiro, do estudo geral pré-universitário, e fornecem instrumentos indispensáveis a um curso capaz de superar o escolaticismo doutrinário.

A primeira destas disciplinas é análise microecômica. Deve ser ensinada de maneira que combine o estudo das idéias e dos métodos básicos - aquilo que é usual no ensino rudimentar de economia - com a introdução ao estudo das con- 
seqüências econômicas de soluções jurídicas diferentes - aquilo que é muito mais difícil e controverso.

Tanto os resultados distributivos de diferentes soluçōes jurídicas quanto seus efeitos para a organização da troca e da produção devem ser objetos de reflexão.

A segunda disciplina de apoio é contabilidade. Sem dominá-la, o aluno não consegue penetrar a vida das empresas nem dominar os instrumentos das finanças públicas. Não é preciso ministrá-la como mero domínio de uma taxonomia. Melhor abordá-la como introduçāo ao estudo das maneiras de descrever e organizar a relação entre os recursos disponíveis às organizaçōes privadas ou públicas e as maneiras de financiá-los.

A terceira disciplina auxiliar é a mais importante: o estudo das ideologias e das instituições. Serve como introdução ao quinto currículo: o currículo das alternativas institucionais. O tema é o conjunto de premissas ideológicas e institucionais que dão vida e sentido ao direito constituído. Um título possível seria: "Ideologias e Instituiçōes no Brasil." Como não é uma disciplina bem definida, tudo depende da qualidade das pessoas que a ministrarem. Uma solução temporária seria tomar como ponto de partida três ou quatro clássicos do pensamento brasileiro, suplementados por textos que retratem o debate brasileiro atual.

\section{O currículo das práticas do direito}

Este terceiro currículo seria destinado apenas àqueles que se orientam para uma vida profissional no direito, como advogados, juízes e membros do Ministério Público. Como o curso de direito que idealizo tem, também, outros objetivos, não há porque exigir este currículo de todos os alunos.

O ideal seria ministrar este currículo em grupos de trabalho de seis a dez estudantes, portanto, a metade ou menos do tamanho típico das aulas características das outras partes do curso. As práticas estudadas seriam as seguintes.

REDACĀO JURÍDICA. Abrange a redação tanto de minutas de contratos, estatutos societários e outros documentos privados quanto de peças processuais. Procura distinguir aquilo que é verdadeiramente útil à escrita técnica do direito daquilo que representa mera concessão ao rebuscado tradicional e obscurantista.

CONSULTORIA. Uma introdução às maneiras de abordar problemas e encontrar soluções alternativas, no trato com clientes privados e públicos. Deve ser ensinado através de uma série de tarefas distribuídas aos diferentes grupos de trabalho de que se compõe o curso.

NEGOCIACÃO. Ensinada como aprendizagem das convergências e dos denominadores comuns, ensaiada em grupos e situaçōes, e vista não só como maneira de evitar ou terminar o litígio como também como maneira de criar um direito vivo. 
PRÁTICAS JUDICIÁRIAS. Os procedimentos escritos e orais, ensinados na maior variedade possível de situações. A idéia é fornecer ao aluno um conjunto de técnicas e formulaçōes básicas.

Todo o currículo das práticas do direito tem um sentido que transcende sua função estritamente profissional: tornar o estudante menos dependente dos escritórios de advocacia com instrumento de formação profissional e fortalecer, com isso, sua independência na escolha de opções e caminhos de carreira.

\section{O currículo da globalização}

Esse currículo introduz o estudante ao direito emergente da economia globalizada. O estudo tradicional do direito internacional, tanto privado quanto públi$\mathrm{co}$, fica inserido dentro de um enfoque prático e atualizado.

O currículo da globalização seria ensinado da mesma maneira que o currículo de direito brasileiro, por uma combinação de abordagem extensiva e aprofundamento seletivo. Abrangeria seis disciplinas.

NOÇŌES DE DIREITO INTERNACIONAL PÚBLICO. Estuda o direito internacional público tal como surge no século 21 , como produto do casamento entre 0 novo ordenamento globalizante e o ius commune que se desenvolvera antes. Aquilo que se concebe tradicionalmente como direito internacional público deve, portanto, ser estudado ao lado do exame das organizações internacionais - sobretudo os das Nações Unidas e do sistema Bretton Woods - e da atuação internacional das organizações da sociedade civil.

NOÇŌES DE DIREITO INTERNACIONAL PRIVADO. Deve ser generalizado como análise dos conflitos e das combinações jurisdicionais - nacionais, subnacionais e supranacionais. Transforma-se, assim, numa espécie de análise combinatória do direito da globalização.

O DIREITO DO MERCOSUL. O estudo deve abranger tanto as normas acertadas quanto as práticas efetivas, à luz das realidades econômicas e políticas subjacentes. Proponho que a análise do direito do Mercosul seja usada como oportunidade para estudar, comparativamente, os blocos regionais de comércio, sobretudo a Comunidade Européia e o Tratado de Livre Comércio da América do Norte. Não é possível compreender a natureza e as possibilidades evolutivas destes blocos sem registrar as diferenças entre os tipos de regionalização e a lógica econômica, política e jurídica de cada um destes tipos.

O DIREITO DA ORDEM INTERNACIONAL DO COMÉRCIO. Compreende tanto as regras e os procedimentos acertados dentro da Organização Internacional do Comércio quanto as regras comerciais que surgem do direito comercial comum ou dos acertos bilaterais entre os países. Não faz sentido dedicar a maior parte do tempo à exegese de normas tão efêmeras e circunstanciais como as que compõem o ordenamento atual. Melhor estudar a nova realidade que se está gerando, sua 
especificidade e sua transformação em um conjunto básico de restrições, sanções e compensaçōes. Importante que o estudo dos contrastes entre os tipos de blocos regionais seja usado para antecipar aquilo que será o tema organizador do último currículo - o repertório de soluções institucionais com que se vai construindo e reconstruindo, mundo afora, a nova ordem.

O DIREITO DO CAPITAL EM MOVIMENTO. O tema dominante é a disciplina - ou a indisciplina - do mercado internacional de capitais e a relação deste mercado com os Estados nacionais e a produção nacional. $O$ tema acessório é o controle jurídico e político das correntes migratórias e a maneira de exercer ou abrandar o contraste entre a mobilidade do capital e a imobilidade do trabalho.

\section{O currículo das alternativas institucionais}

O último currículo - e o coroamento de todo o curso - seria o currículo das alternativas institucionais. Seria de interesse mais direto dos que preparam uma carreira na vida pública ou nos negócios internacionais bem como dos advogados que queiram atuar em problemas da economia globalizada. Só não teria interesse prático mais imediato para quem imagine desenvolver uma vida profissional exclusivamente dentro do Brasil ou do direito brasileiro.

Ao mesmo tempo que serve a uma preocupação prática, esse currículo ajuda a formar quadros dirigentes capazes de formularem um rumo próprio para o Brasil: um conjunto de estratégias da nação, com conteúdo institucional próprio. Ajuda a criar condiçōes para que nos libertemos da cultura da cópia e da tendência ao fatalismo. Estimula-nos a repensar as formas institucionais da economia de mercado, da democracia e da sociedade civil livre, superando a idéia de que só nos cabe humanizar, através de políticas sociais compensatórias, o mercado globalizado.

A idéia central do currículo das alternativas institucionais é que as formas de organização política, econômica e social disponíveis no mundo depois do colapso do comunismo se compōem de um repertório, restrito e relativamente inelástico, de maneiras de organizar cada campo da vida social. Essas soluçōes institucionais aparecem num nível de detalhamento mais concreto do que o permitido pelas abstraçōes tradicionais do debate ideológico, conceitos como capitalismo ou economia de mercado. E cada uma das variações que integram o repertório institucional contemporâneo existe, e é pensada, como direito.

Um exemplo conhecido quase banal é a discussão dos tipos de "corporate governance": as regras e as práticas que definem as relaçōes entre os proprietários das empresas, seus gestores, o mercado acionário e o mercado de capitais. Tais regras e práticas convergem para compor regimes jurídicos da empresa. Compreender como funciona cada um desses regimes é começar a dominar todo um sistema de direito societário e a entender a relação entre as soluções que ele possibilita e os problemas que a vida real dos negócios gera. 
Há a tese de que o modelo americano de empresas abertas, com gestores profissionais, responsáveis a acionistas difusos e preocupados em aumentar a curto prazo o valor das açōes é o regime que tende a se impor em todo o mundo. A sanção de última instância contra uma gestão que, sem levar a empresa à falência, deixa de maximizar seu valor é uma aquisição hostil da empresa no mercado acionário. Os modelos alemães e japoneses, que privilegiam relaçōes de propriedade e controle recíproco entre empresas, ou entre empresas e bancos, estariam em decadência, incapazes de sustentar aumentos constantes de eficiência e produtividade e triunfar diante da concorrência internacional aguçada.

Já outra tese responde que embora tais alternativas sofram, na sua forma atual, de uma rigidez custosa também favorecem o investimento na capacitação da força de trabalho e o desenvolvimento de relações de confiança entre os trabalhadores e os gestores. Daí por que a social-democracia européia, com seu zelo pela proteção social contra as consequiências da instabilidade dos mercados de produtos, trabalho e capital, não se conformaria com a adoção do modelo americano. Um novo modelo, diferente tanto do americano quanto do alemão ou japonês anterior, estaria em gestação. Compreender as idéias e as forças em jogo nessa transição é o primeiro passo para dominar outro regime atual de direito societário, sua doutrina e sua prática.

Retorno à tese hegeliana do direito como vida de um povo, organizada em instituiçōes. A situação atual, porém, não é, se em algum momento foi, aquela descrita pelos historicistas alemães. Não há divisōes estanques entre as soluções institucionais adotadas pelos diferentes povos. Todos se organizam pela pilhagem do mesmo estoque limitado de soluções institucionais, combinando, adaptando e renovando elementos da maneira que lhes convém. Dessa circunstância resultam duas ordens de oportunidades, uma para o advogado, outra para o reformador.

Para o advogado prático que queira exercer sua profissão junto aos negócios da economia globalizada, há um problema a resolver. A integração econômica coexiste com a diversidade política e jurídica. Não há, porém, como dominar o direito de muitos países: as regras, os procedimentos e as práticas. Seria um esforço hercúleo e frívolo que o deixaria sempre a braços com pormenores ao mesmo tempo infindáveis e efêmeros. Quando combinado com o estudo do direito internacional (o currículo da globalização), o domínio do repertório mundial de soluções institucionais básicas fornece uma solução.

Conhecendo os elementos básicos que são os rudimentos institucionais de cada sistema nacional de organização jurídica da sociedade, é possível mover-se com desenvoltura entre os detalhes técnicos. Quem conhece bem os elementos com que se compõem os ordenamentos nacionais poderá compreender com rapidez as composiçōes resultantes. Pode atuar universalmente sem ter conhecimento universal - pré-requisito para a atividade profissional de primeiro nível no mundo que está surgindo. 
Para o reformador, o estudo do repertório da economia globalizada abre o caminho de um pensamento inventivo e realista. Pois o ponto de partida para a prática das reformas no mundo atual costuma ser o esforço para ampliar, por extensão analógica ou por recombinação dos elementos disponíveis, o repertório institucional existente. $O$ estudo das variações institucionais existentes leva, naturalmente, à investigação das alternativas institucionais. Em vez de serem concebidas como sistemas prontos e indivisíveis, as alternativas passam a ser vistas como construções com os materiais existentes, como "bricolage". O que transforma a "bricolage" em projeto, como sentido exemplar para a humanidade, é seu casamento com uma visão transformadora.

Entre as regras técnicas e as abstrações filosóficas, está o nível intermediário em que se colocam as questōes cruciais da organização e da reorganizaçāo da sociedade. Neste nível está a vantagem comparativa do jurista. O direito é o lugar privilegiado onde práticas e instituições se encontram com interesses e ideais, com toda a riqueza de uma realidade histórica e singular. Aproveitar essa vantagem comparativa é o objetivo do currículo das alternativas institucionais.

Supondo que haja um número menor de alunos, e dada a natureza vanguardista deste currículo, proponho ensiná-lo em grupos de seis a dez alunos, tal como o currículo das práticas judiciárias. E, por causa de sua natureza de estudo avançado, seria possível configurá-lo, também, como um programa diferenciado de mestrado.

O método predominante não seria mais a combinação de introdução informativa e aprofundamento seletivo, característica da maior parte dos outros currículos. Seria a investigação e análise em pequeno grupo, com o professor como líder, dos mecanismos institucionais disponíveis no mundo em cada uma das principais áreas da vida social, e a reflexão sobre alternativas possíveis sugeridas pelas variaçōes institucionais conhecidas existentes. Alunos e professores viveriam a experiência de grupos de pesquisa, característica das formas mais avançadas do trabalho científico e profissional.

Em vez de divisões rígidas de disciplinas, haveria um elenco fluido de campos de pesquisa. Enumero alguns, apenas a título de exemplificação:

- Estado e a política.

- A empresa, seus controladores, acionistas, gerentes e trabalhadores.

- A organização da propriedade e da concorrência.

- As profissōes e o público.

- A família, a criança e a escola.

- A poupança, o crédito, o dinheiro e a produção.

- A violência e seu controle. 
É como se retomasse todo o currículo de direito brasileiro, com duas diferenças fundamentais. O enfoque passa daquilo que vige no Brasil para aquilo que está disponível em todo o mundo e das regras e políticas constituídas para a estrutura profunda das opções e das premissas institucionais.

A mentalidade dominante oscila entre a idéia de estar perdido numa floresta de arbitrariedades contingentes - tudo poderia ser diferente - e a concepção oposta, de estar preso dentro de um sistema de forças inescapáveis. O acaso e o destino. $\mathrm{O}$ entendimento e a ação exigem substituir ambas as concepções supersticiosas pela visão de uma realidade que se pode decompor e recompor, parte por parte e passo por passo. Alcançar este poder do intelecto e da vontade é o objetivo superior não só do currículo das alternativas institucionais mas também de toda esta proposta para inaugurar um novo ensino de direito no Brasil. Um ensino que ofereça ao Brasil melhores condiçōes para tornar fecunda sua afirmação nacional. 